\title{
Volitional regulation and performance of sports gifted young athletes
}

\author{
Natalya Ulyanova* and Oksana Chernykh \\ Don State Technical University, Faculty "Psychology, Pedagogy and Defectology", Rostov-on-Don, \\ Russia
}

\begin{abstract}
The empirical study of the involvement of personal volition in the athletic success of young athletes aged 9 to 18 yearsis presented. The purpose of this study was to examine the relationship between individual characteristics of volitional processes and the grade of sport performance, determined by the sports qualifications of the respondents. The specifics and requirements ofdifferent kinds of sport have been considered. At the sample of young athletes from 9 to 18 years old ( $N=145, M=13,2$ years) for some sports (athletics, rock climbing, football)significant regression models were built. Particular characteristics of volitional processes or their combination were discovered as predictors, and the athlete's performance was a dependent variable. For other sports disciplines (boxing, rowing, swimming, rhythmic gymnastics), such models could not be identified. Moreover, we established that emotional self-control and determination have a joint effect on the grade of sport performance of athletes who was younger than 13 , while for athletesfrom 14 to 18 years oldcommon predictors of performance from among volitional qualities was not found.
\end{abstract}

\section{Introduction}

Sports giftedness is aproblem that attracts the attention of many researchers. Participation in international sports is associated with defending of the honour of your country, and the achievements of Olympic champions or national teams become national triumph. It is widely known that the high achievements sports are inextricably linked with the support system of gifted children and young athletes [1]. Achieving outstanding results is usually associated with identifying athletic talent at an early age and continuous skills developing using a system of increasingly sophisticated training. At the same time, along with physical training, a lot of importance is given to psychological support of athletes during training periods, game preparations and competitions [2].

Sports psychology especially emphasizes the issue of volition. Studies continue to show the existence of strong correlations of athletes' success with determination and self-control [3], autonomy [4], persistence [5], etc. Scientists have also identified relationships that are more complex. For example, personal cognitive characteristics such as self-control, information processing, etc. turn out to be mediating factors of relationship between athletic success and

\footnotetext{
* Corresponding author: n.y.ulyanova@gmail.com
} 
volition [6]; psychological and life skills [7], moral attitudes [8]. Thus, the tasks of psychological support for training athletes traditionally include the formation of such emotional and volitional qualities as self-determination, perseverance, decisiveness, initiative, etc. [9]. However, there are evidence that we should take more differentiated approach to the psychological work with athletes. Thus, specific requirements of different sports become an important factor that affects the professional significance of certain volitional qualities. In a Russian study based on the method of expert assessments, it was shown that courage, bravery, emotional self-control and risk tolerance among else are important in sports games (football, basketball, etc.); complaisance and a sense of duty are important in martial arts; and attentiveness, concentration, self-regulationdefine performancein complex coordination sports (gymnastics, figure skating, etc.) [10]. There are studies dedicated to understanding the influence of volition on the level of achievements in certain sports: climbing [11], hockey [12], boxing [13], etc. At the same time, the number of works in which conducted a comparative analysis of the relationship of emotional and volitional characteristics and the real success of athletes engaged in different disciplines, is not too great.

Another factor that is important for understanding the role of psychological support at different stages of sports training is the athletes' age. As the gifted children and adolescents grow older, the tasks and conditions of their activity changes: the complexity of training increases, dropout rates become higher, competitive selection tightens, etc. On the one hand, this enhances the role of psychological factors in sports achievements, and on the other hand, the ongoing pressure of selection and attrition leads to the fact that only the most motivated boys and girls remain in sports. Thus, in the early stages of sports training, the significance of the volitional component is higher than in the later ones, when an interest in sports and motivation become self-sustaining [14]. Researchers emphasize the key role of childhood [15] and adolescence [16] in the development of volition in young athletes. However, the question of the specific tasks in the psychologists work and psychological and pedagogical support at different stages of training remains open.

The lack of knowledge on the problem determined the goal of our research: to study the relationship between the volition and the athlete's performance of sports-gifted children and adolescents, taking into account their age differences.

\section{Hypotheses 1.}

Volition makes a differentiated contribution to the athlete's performance of young athletes involved in various sports.

\section{Hypotheses 2.}

The volitional processes'contribution to sport performance is stronger in children than in adolescent athletes.

\section{Method}

\section{Participants}

The study involved 145 participants, including $42 \%$ of girls and $58 \%$ of boys - students of the Rostov Academy of Olympic Reserve and youth sports schools of Rostov-on-Don and the Rostov region aged 9 to 18 years $(M=13.2$ years $)$.

\section{Measures}


To determine the objective indicators of sport performance, we asked respondents to indicate their sports qualifications (assigned sports rank) and sports discipline. Rank scale was used as an indicator of sports success: each respondent was assigned a rank from 1 to 8 in accordance with the assigned sports category: 8 points corresponded to the category "Master of Sports", 7 - "Candidate Master of Sports", 3 - "First-Class Sportsman", etc .; 1 point corresponded to the qualification "Third-Class Junior Sportsman".

Personal characteristics of volitional processes were investigated using psychological testing: "Psychological analysis of the development of the volitional qualities of athletes" (B. N. Smirnov, 1989) (studied variables: determination, perseverance, decisiveness, endurance, autonomy); "Identifying the severity of self-control Questionnaire" (G. $S$. Nikiforov et al., 1989) (studied variables: tendency to self-control in emotions, tendency to anticipating self-control in activities, tendency to current self-control in activities, tendency to social self-control); "Self-assessment of organization" (E. P. Ilyin, 2002) (studied variable: organization). The standardization of primary data was carried out by transferring "raw" test scores into the Z-scale, research hypotheses were tested using multiple regression.

\section{Results}

Research hypotheses were tested using stepwise regression. Dependent variables were the ranks corresponding to the level of sports qualifications; characteristics of volitional processes were predictors. First, we analyzed the data of the whole sample. As a result, not one of the volitional processes characteristics entered the regression model at a statistically significant level.

Then we grouped the data in accordance with the types of sports disciplines: athletics, rowing, kayaking and canoeing, swimming, climbing, football, boxing, rhythmic gymnastics. Table 1 presents results of the regression analysis.

Table 1. The results of multiple regression analysis of the relationship of volitional processes characteristics and the success of athletes involved in various sports

\begin{tabular}{|c|c|c|c|c|}
\hline \multirow{2}{*}{$\begin{array}{c}\text { Grouping variable } \\
\text { (sport) }\end{array}$} & \multirow{2}{*}{ Independent variables } & \multicolumn{3}{|c|}{ Model parameters } \\
\hline & & $R^{2}$ adjusted & $\beta$ & $p$ \\
\hline \multirow{2}{*}{ Athletics } & General self-control & \multirow{2}{*}{0.20} & 0.41 & 0.01 \\
\hline & Social self-control & & -0.34 & 0.03 \\
\hline Swimming & Endurance & 0.06 & -0.29 & 0.05 \\
\hline $\begin{array}{l}\text { Kayaking and } \\
\text { Canoeing }\end{array}$ & Decisiveness & 0.08 & -0.96 & 0.04 \\
\hline \multirow{2}{*}{ Rock climbing } & Emotional self-control & \multirow{2}{*}{0.32} & -1.39 & 0.01 \\
\hline & Endurance & & 0.52 & 0.04 \\
\hline Football & Social self-control & 0.21 & 0.37 & 0.02 \\
\hline
\end{tabular}

Note: The dependent variable is the sports qualification.

The obtained data allow us to conclude that for athletes involved in athletics, swimming, kayaking, climbing, football, one or a combination of two independent variables, contribute significantly $(\mathrm{p} \leq 0.01$ or $\mathrm{p} \leq 0.05)$ to the athletic success; for athletes involved in rowing, boxing and rhythmic gymnastics, none of the volitional processes characteristics enter the regression model. Moreover, the coefficient of determination of regression models (adjusted $R^{2}$ ) for the athletics, rock climbing and soccer is significantly higher $\left(R^{2} \geq 0.20\right)$ than for the swimming and kayaking and canoeing $\left(\mathrm{R}^{2}<0.10\right)$. 
Next, we turn to the analysis of the data grouped according to the age of the respondents: the youngest group is from 9 to 13 years old $(53.1 \%$ of the total sample), the older group is from 14 to 18 years old $(46.9 \%)$. Table 2 presents results of the regression analysis considering indicated age groups.

Table 2. The results of multiple regression analysis of the relationship of volitional processes characteristics and the success of athletes differentiated by age

\begin{tabular}{|c|l|c|c|c|}
\hline \multirow{2}{*}{ Grouping variable (age) } & \multirow{2}{*}{ Independent variables } & \multicolumn{3}{|c|}{ Model parameters } \\
\cline { 5 - 5 } & & $R^{2}$ adjusted & $\beta$ & $p$ \\
\hline \multirow{2}{*}{$9-13$ years } & Emotional self-control & \multirow{2}{*}{0.36} & 0.51 & 0.01 \\
\cline { 2 - 3 } \cline { 4 - 5 } & Determination & & 0.37 & 0.04 \\
\hline
\end{tabular}

Note: The dependent variable is the sports qualification.

The data obtained indicate that not one of the volitional processes characteristics acted as a predictor of sports success for athletes of the older age group. For the younger age group, it turned out to be significant the model, where such volitional processes characteristics as "Emotional self-control" and "Determination" acted as predictors, and the determination coefficient turned out to be relatively high $\left(\mathrm{R}^{2}=0.36\right)$.

\section{Discussion}

Since the regression analysis of the effect of volitional processes characteristics on the athletic success had no statistically significant results, we assume that for sports-gifted children and adolescents there is no "universal" component of emotional-volitional development that could definitely be considered as a predictor of future achievements. The absence of statistically significant models of the relationship between the volitional processes characteristics and athletic success, of course, does not mean the absence of the effect of the volitional qualities of athletes on their performance. However, it definitely indicates the complexity of the nature of its effect, which is probably mediated by a significant number of internal and external factors. This result indirectly confirms our assumption that the generalized models of psychological support for gifted athletes are ineffective. Thus, it is necessary to develop differentiated work strategies taking into account the specifics of age development and requirements of different sports.

Our results of a regression analysis of the relationship between the volitional processes characteristics and the level of sports achievements taking into account sports disciplines can be divided into two groups: models with statistically insignificant or low coefficients of determination $\left(\mathrm{R}^{2}<0.10\right)$ and models with relatively high coefficients of determination $\left(\mathrm{R}^{2}\right.$ $\geq 0.20$ ).

In accordance with the data obtained, we can assume that for athletes involved in swimming, rowing, boxing and rhythmic gymnastics, the development of volitional qualities is not the dominant factor in achieving athletic success. At the same time, volition can have an indirect or indirect effect in combination with other variables (functional characteristics of neurodynamic activity, cognitive characteristics, training and competition conditions, etc.) that were not included in this study.

The data obtained in groups of athletes, climbers and football players are the most interesting for interpretation. For these groups, the constructed regression models included one or two predictors from characteristics volitional processes and had a relatively high coefficient of determination (Total Variance Explained 20\% to 32\%). All three models 
included indicators of self-control in a particular area, and for different sports, these indicators can make both a positive $(\beta>0)$ and a negative $(\beta<0)$ effect on the athletic success. So, for a group involved in athletics, a high level of sports achievements is associated with a high level of general self-control and a low level of social self-control, while for football players, great performance, on the contrary, is associated with a high level of social self-control. This result is clearly consistent with the specifics of sports disciplines: athletics is about achieving individual results and involves a lot of competition even within the national or regional team; and for football players, on the contrary, mutual support and team cooperation is an extremely important condition for a successful performance. At the same time, general self-control, which is a significant predictor of success in strictly regulated by the rules of performance technique athletics, is not included in the list of significant predictors in more varied and socially oriented football. For climbing, the level of achievements turned out to be negatively associated with emotional self-control and positively with endurance. This is also clearly in agreement with the conditions of training and competing in this discipline, which implies general adrenaline rush, need of quick making tactical, often intuitive decisions, as well as the athletes' willingness to endure the enormous weight loads, when the body weight has to be supported with their fingertips without falling off a mountain or climbing wall. Thus, various volitional qualities can contribute to the level of gifted athletes' achievements both positively and negatively, depending on the requirements of a particular sport.

The regression analysis results regarding the effect of volitional processes characteristics on the athletic success of athletes of different age groups showed that for younger group (9-13 years old) significant was the model included two predictors: emotional self-control and determination. Both variables have a positive effect on the level of sports achievements, while the coefficient of determination of the regression model is quite high $\left(\mathrm{R}^{2}=0.36\right)$. Age-related features of this developmental period include high emotional lability, instability of concentration and voluntary attention. Therefore, it seems quite logical that the greatest success is accomplished by those adolescents who have greater capability for self-control and perseverance in achieving their goals than their peers. Whereas, for older adolescents and youths (14-18 years old), not a single variable was identified from the number of volitional processes characteristics that would significantly affect the level of sports achievements. We believe that this may be due to several reasons. First of all, a there is certain intrinsic discrepancy in sports qualification system. "Master of Sports" and "Candidate Master of Sports" ranks require much more effort, time and training in comparison with other, lower qualification ranks. So, it is important to take that into account when we use sports qualifications as an indicator of athletic success. Secondly, as athletes grow older, dropout rates become higher, their training becomes more and more professional, internal team competition tightens. That means that only the most motivated children and adolescents remain in sports. Finally, general physical training is no longer of decisive importance. Training of discipline-specific skills (including psychological) becomes the objective. Therefore, it becomes impossible to single out the "universal" characteristics of the volition, which determines the high level of athletic success.

\section{Conclusions}

Thus, as a result of the research conducted in sports-gifted children and adolescents, the following conclusions can be drawn:

1. Volition contributes to the athlete's performance of sports-gifted children and adolescents. However, the nature of this contribution is ambiguous and depends on the 
specifics and requirements of different sports and training objectives associated with particular discipline.

2. For some sports (athletics, rock climbing, football), it is possible to identify the effect of individual characteristics of volitional processes (or their combination) on the level of athletic success. For other disciplines (boxing, rowing, swimming, rhythmic gymnastics), the relationship of volition and the level of sports achievements, apparently, is largely mediated by other variables.

3. At the early stages of training young athletes, such indicators of volitional regulation as emotional self-control and determination have a joint effect on the level of sports achievements, at later stages the influence of volition on athletic success becomes less clear.

4. The psychological support of athletically gifted youth, including in the field of supporting emotional-volitional development, requires a differentiated approach, which includes taking into account the age characteristics of athletes as well as training objectives of particular discipline they involved.

\section{References}

1. R. Vaeyens, M. Lenoir, A. M. Williams, R. M. Philippaerts, Sports Med., 38 (9), 703-714 (2008).

2. A. R. Nicholls, Psychology in sports coaching: theory and practice (Routledge, N.Y., 2017).

3. L. Behncke, Athl. Ins., 14 (1), 313-325 (2002).

4. K. Hodge, C. Lonsdale, J. of Sport and Ex. Psych., 33 (4), 527-547 (2011).

5. H. Jõesaar, V. Hein, M. S. Hagger, Psych. of Sport and Ex., 12 (5), 500-508 (2011).

6. J. M. Keller, Techn., Instr., Cogn., and Learn., 6 (2), 79-104 (2008).

7. D. Birrer, G. Morgan, Scand. J. of Med. \& Science in Sports, 20, 78-87 (2010).

8. N. Ntoumanis, M. Standage, J.of App. Sport Psych., 21 (4), 365-380 (2009).

9. T. V. Ryba, N. B. Stambulova, C. A. Wrisberg, Int. J. of Sport and Ex. Psych., 7 (3), 275-291 (2009).

10. N. Vysochina, A. Vorobiova, M. Vasylenko, F. Vysochin, J. of Phys. Ed. and Sport, 18 (1), 230-234 (2018).

11. D. MacLeod, D. L. Sutherland, L. Buntin, A. Whitaker, T. Aitchison, I. Watt, S. Grant, J. of Sports Sciences, 25 (12), 1433-1443 (2007).

12. R. Zheng, Ch. Wint. Sports, 6, 6. (2009).

13. L. Yong, J. of Wuhan Inst. of Phys. Ed., 6, 23-27 (2001).

14. M. R. Weiss, President's Council on Phys. Fit. and Sports Research Digest. (2000).

15. A. D. Baxter-Jones, Sports Med., 20 (2), 59-64 (1995).

16. P. Feichtinger, O. Höner, Eur. J. of Sport Science, 15 (8), 748-756 (2015). 